\title{
SOCIAL NORMS, THE INVISIBLE HAND, AND THE LAW
}

\author{
JONNY ANOMALY ${ }^{1}$ AND GEOFFREY BRENNAN ${ }^{2}$
}

Social norms can be oppressive or empowering; and so can laws. Norms are sometimes described as emergent rules or behavioural regularities that arise as solutions to collective action problems of various kinds faced by individuals when they interact with each other. Examples include rules of combat, courtship rituals, and informal systems of property rights that determine what members of a group can do with the food they gather and the objects they create, or whom they can marry. ${ }^{3}$

The emergence and internalization of norms generally involves an invisible hand process similar to Darwin's idea of natural selection in biology or Smith's account of the operations of markets in economics. In some cases, these 'invisible processes' will be welfare-enhancing, and when they are, we will refer to them as invisible hands. ${ }^{4}$ In welfare-enhancing cases, a common thought is that the process in which a particular norm emerges as the prevailing one involves norms being tried out, with those that diminish welfare being filtered out over time, so that through a bottom-up, trial-anderror process, welfare-enhancing norms emerge victorious and are preserved and replicated. Of course, social evolution does not always work like this, and people can be trapped at equilibria that are mutually destructive or suboptimal (we call these invisible fists).

The bottom-up emergence of norms is often contrasted with the top-down imposition of legislation by larger political units, which tends to displace or alter norms. But this contrast is too stark. For example, in representative governments laws emerge from the interactions of policymakers and citizens, without any one person wielding the power to impose top-down rules on passive subjects. Moreover, politicians and voters are themselves subject to prevailing norms, which influence the content of the laws that are enacted. ${ }^{5}$ And the institutions within which policy-makers and policy-takers interact are also governed by 'process norms' - concerning, say, who has voice and how collective decisions are appropriately made.

In this paper we argue that social norms are emergent orders; that when they are welfare-enhancing they constitute invisible hand processes; and that whether we should rely more heavily on laws or norms to improve social welfare depends on the political institutions in place and the nature of the case under consideration. In other words, we argue that there is no general answer to the question of whether norms or laws should prevail, in part because both emerge from imperfect, path-dependent processes that have their own distinctive advantages and disadvantages. We do, however, suggest some general conditions under which it might be better to rely on laws or on norms to enhance social welfare.

Duke University and UNC Chapel Hill.

Australian National University, Duke University and UNC Chapel Hill.

Elinor Ostrom's work on informal property rights is an influential example of how norms can solve collective action problems. See especially 'Collective Action and the Evolution of Social Norms' (2000) 14(3) The Journal of Economic Perspectives 137.

4 This nomenclature is not universal. We shall discuss our reasons for it in section 2 below.

5 Indeed, it might be argued that norms play a disproportionate role in electoral processes as compared with market behaviour. For more on this, see Geoffrey Brennan and Loren Lomasky, Democracy and Decision (Cambridge University Press, 1991). 


\section{SOCIAL NORMS AS EMERGENT ORDERS}

As Suri Ratnapala observes, '[t]he idea that all law stems from the will of an identifiable law maker remains influential in law schools despite being contradicted by the natural history of the human race and by what we know of contemporary society' 6 Like Hayek and Leoni before him, Ratnapala distinguishes law from legislation, and argues against the legal positivist tendency to regard legislation as the primary source of social order. ${ }^{7}$ We broadly agree with Ratnapala on this, though we prefer to contrast norms with laws and maintain the contemporary convention of equating law with legislation. Throughout the essay, we shall use 'norms' and 'social norms' interchangeably. ${ }^{8}$

By laws, then, we mean legislation, usually backed by sanctions, promulgated from a formal government with the power to enforce the terms of that legislation on its citizens. By norms we mean, roughly, the informal rules that govern the behaviour of members of a group. But this is just a first pass.

In an influential article, Richard McAdams defines norms as informal social regularities that individuals feel obligated to follow because of an internalized sense of duty, because of fear of external non-legal sanctions, or both'. ${ }^{9}$ This is a plausible definition of social norms that apply to a particular group whose members 'feel obligated to follow' them. But since social rules or regularities change over time, and differ between groups, regularities do not need to make everyone (including dissenters, outsiders, and social scientists) feel obligated to follow them in order to count as norms. Robert Ellickson provides a simpler definition of social norms as 'rules governing an individual's behaviour that third parties other than state agents diffusely enforce by means of social sanctions'. ${ }^{10}$ To this we should add that for a rule to exist as a norm for a particular group, enough people within the group must believe they should follow it. ${ }^{11}$ Norms are, in this sense, normative: they are action-guiding rules or procedures that govern the behaviour of members of a group.

What it means for individuals to follow the norm will be broadly interpreted. Suppose, for example, that there are norms of good performance in an activity like operatic singing which are widely endorsed and are used to determine the quality of

6 Suri Ratnapala, 'Eighteenth Century Evolutionary Thought and its Relevance in the Age of Legislation' (2001) 12 Constitutional Political Economy 51, 52.

7 Friedrich Hayek and Bruno Leoni often contrast laws, by which they mean social norms (especially norms reflected in English common law), with legislation, by which they mean rules promulgated by a legislature. We think this distinction is worth preserving but the terminology is unnecessarily confusing, so we stick with the typical contrast between social norms and (legislated) laws. See Friedrich Hayek, The Constitution of Liberty (University of Chicago Press, 2011) ch 4; and Bruno Leoni, Freedom and the Law (Liberty Fund, 1991).

8 We concede that the term 'norm' is both vague and ambiguous. But we are interested in social norms that regulate social behaviour, rather than personal norms that guide private behaviour. In the law and economics tradition, we ignore personal norms, like New Year's resolutions or vows to drink less coffee, and focus instead on rules or regularities that arise in response to conflicts between individual rationality and collective welfare. For a detailed discussion of the many uses of the term 'norm' see Geoffrey Brennan, Lina Eriksson, Robert E Goodin and Nicholas Southwood, Explaining Norms (Oxford University Press, 2013).

9 Richard McAdams, 'The Origin, Development, and Regulation of Norms' (1997) 96(2) Michigan Law Review 340.

10 Robert Ellickson, 'The Market for Social Norms' (2001) 3(1) American Law and Economics Review 3.

11 Cristina Bicchieri argues that 'the very existence of a social norm depends on a sufficient number of people believing that it exists and pertains to a given type of situation, and expecting that enough other people are following it in those kinds of situations': The Grammar of Society: The Nature and Dynamics of Social Norms (Cambridge University Press, 2005) 2. 
different singers. Not everyone is a singer - and even those who are singers might not aspire to professional status - so not everyone observes the relevant norms in their own singing. But those norms determine what criteria the general bulk of opera singers adopt to evaluate performance and hence the level of esteem and disesteem that different performers receive. In a similar sense, there may be norms of heroism in the military that all soldiers aspire to, but only a small number realize in their conduct. We think that these qualify as norms because a) they are widely endorsed within the relevant community (of singers/soldiers), and b) they establish esteem-based incentives for individual soldiers to act more heroically or singers to strive to meet the norms of good singing. They stand as norms even though few soldiers actually qualify as heroes or singers as maestros. In short, we wish to use a more expansive notion of norms than some other theorists of the subject adopt: we do not think it necessary that a majority of individuals exhibit compliance with the norm in their own behaviour. It may be sufficient that they exhibit compliance in their evaluation.

Norms can be understood as emerging within social groups to solve collective action problems in which there is a conflict between individual rationality and social welfare. On Cristina Bicchieri's view, 'we need social norms in all those situations in which there is a conflict of interest but also a potential for joint gain'. ${ }^{12}$ On this view, norms can transform what begin as negative sum games like prisoner's dilemmas into coordination games in which all parties benefit. ${ }^{13}$

Usually coordination games are impure, since group members have preferences over different possible equilibria in the feasible set. For example, suppose people in a tribe living in Madagascar notice that many of their members are not careful about cleaning up the carcasses of animals they eat. This creates noxious smells, attracts predators, and raises the risk of infectious diseases that all of them would prefer not to endure. In the absence of explicit property rights or rules that require everyone to dispose of animal carcasses in a more hygienic way, each individual has a strong incentive to carry on with the collectively harmful practice since each only bears a fraction of the cost of the problem, but gets the full benefit of not exerting extra energy to clean up carcasses. In other words, the outcome is a Pareto-inferior Nash equilibrium, and the game is an n-person prisoner's dilemma.

Now suppose the tribe members understand the problem and at least some of them seek a way to solve it. Perhaps a 'norm entrepreneur' - someone with exceptional charisma and leadership - proposes several solutions. ${ }^{14}$ This entrepreneur may lack the power (or influence) to impose any new norm unilaterally, but he may persuade a few tribesmen to change their behaviour, and encourage them to criticize those who do not. Others propose alternative social rules, or simply imitate how people around them are

12 Ibid 3

13 We might say that norms often serve this function: but of course it requires extra argument to show that serving that function helps explain a norm's existence. However, we think that requirement is a weak one. After all, the function attributes of norms only have to play some role in the explanation of their existence. The fact that norms solve certain collective action problems can be a contributory factor in accounting for their origin or for the maintenance of the norm in particular cases, without any claim that this line of explanation is the entire story. As Bentham put the point in a slightly different connection, the fact that rights serve a particular social function no more ensures that rights will emerge than the fact of hunger is sufficient to supply bread! - Jeremy Bentham, Anarchical Fallacies; Being an Examination of the Declarations of Rights (Simpkin, Marshall, \& Co., 1843) 501.

14 Ellickson, above n 10,12. Robert Ellickson defines 'norm entrepreneurs' as people in a group with 'superior technical intelligence, social intelligence, and leadership skills'. He adapts the term from Cass Sunstein, who defines them more generally as 'people interested in changing social norms': 'Social Norms and Social Roles' (1996) 96(4) Columbia Law Review 909. 
acting, and eventually the group converges on a particular norm, or equilibrium, which no individual had the power to impose.

\begin{tabular}{|c|c|c|c|c|}
\hline & \multicolumn{3}{|c|}{ Thor } & \multirow[b]{2}{*}{ Burn } \\
\hline & & Carry & Bury & \\
\hline \multirow{3}{*}{ Odin } & Carry & 25,30 & 20,15 & 5,10 \\
\hline & Bury & 10,5 & $\mathbf{3 5 , 3 0}$ & 10,10 \\
\hline & Burn & 5,5 & 15,10 & 20,25 \\
\hline
\end{tabular}

Why does convergence on a norm produce net benefits? In this case, assume that each member of the group understands the problem and is willing to follow a rule. Each is made better off by following one rule because it saves time, creates social harmony, and possibly brings economies of scale, such as one big pit where animal carcasses are burned or buried, or one spot in the woods along a clearly marked path where carcasses are dumped. Transaction costs are reduced and social costs are minimized by converging on a single method of disposal.

Different methods of disposal may well be preferred by different people perhaps because they are used to doing things a certain way, because they prefer digging holes to lighting fires, or because some people live close to the proposed burial ground or fire pit and have to endure the extra noise or odor that comes with living near a disposal site. In this case, as in many real world examples, the equilibrium that emerges may not be socially optimal, and none of the equilibria will satisfy everyone equally. But once a norm emerges as an equilibrium of the game, it becomes a selfenforcing convention. ${ }^{15}$ The stability of norms in cases like this leads Eric Posner to say, somewhat reductively, that a 'social norm is just the label we attach to equilibrium behavior'. 16

We think that Posner's description is inadequate because it overlooks the distinctive normative force that attaches to some norms. Some equilibria just are emergent properties. But in such cases, should external conditions change, the equilibrium can change without any additional forces being invoked to restore the prevailing practice. What is characteristic of norms is that compliance is buttressed by additional incentives - by internal or external sanctions that reflect the norm's status as a norm. Put another way, not all equilibria are sustained in the same way. Some are sustained solely by the objective payoffs - in our example, the reduced disease and more pleasant ambient aromas that are associated with carcass removal. Others are sustained (as well) by the fact that if you do not comply with the prevailing practice, you will be the object of contempt, and perhaps risk more material punishments, like being excluded from agreeable social activities (including, possibly, exchange of goods). The issue in explaining norms is not whether norm-governed behaviour constitutes an equilibrium, but rather what the equilibrating forces are. Not all social equilibria involve norms, and not all norms are social equilibria.

15 See Thomas Schelling, Micromotives and Macrobehaviour (W. W. Norton \& Co, 2006) ch 3.

16 Eric Posner, Law and Social Norms (Harvard University Press, 2002) 58. 
The point is important because it bears on the question of how norms can transform collective action problems into coordination games with salient equilibria. The most general answers are through external sanctions like punishment, on the one hand, and through internal sanctions like guilt and shame, on the other. Shame occurs when an individual believes he has violated a social norm that others are in a position to detect, and believes others will disapprove of him as a result. Guilt occurs when an individual has internalized a social norm, believes he has violated it, and imposes a kind of internal sanction on himself as punishment for doing what he believes is unfair, immoral, or otherwise wrong, even when he knows nobody else knows about it. External sanctions are costly in time and resources, ${ }^{17}$ and in some situations guilt and shame will achieve the same result at lower cost. Indeed, it is plausible to suppose that moral emotions like guilt and shame may have evolved to minimize conflict among members of close-knit groups. ${ }^{18}$

Since there is often a conflict between individual and group interests, different individuals are likely to experience different levels of guilt and shame for the same transgression, and it may be that threats of external sanctions are necessary to nudge many people to comply with norms. In political societies, sanctions can take the form of fines, prison sentences, and property seizures. But political sanctions are expensive to enforce, and even when legal rules are clear, people often turn to social norms to solve day to day disputes when the combination of internal sanctions like guilt and shame and external but informal sanctions like social stigma are sufficient to incentivize people to act in socially beneficial ways. ${ }^{19}$

Social sanctions for violating norms often involve stigma, or diminished social standing, and this can mean fewer opportunities to trade, reduced access to mates or food, less security and protection from other members of a group, and (in extreme cases) threats of physical harm. But if, as Adam Smith thought, the desire for the good opinion of others is hard-wired into our psychological makeup, then individuals will be led to seek other people's esteem even when there are no further consequences. So in cases where guilt is insufficient to coax individuals to comply with norms, social sanctions are important, and these need involve nothing more than the knowledge that observers disapprove of those who violate norms, or approve of those who abide by them. No central authority is involved. Moreover, where the would-be violator is not anonymous, and thus capable of bearing a reputation, esteem incentives can be reinforced in a simple and familiar way: gossip.

Gossip would seem like a waste of time and energy for the people who engage in it, since monitoring social infractions and sharing information are public goods. Gossipers incur the full costs of gathering and spreading information, but only get a fraction of the benefits, which are dispersed among the entire group. The fact that useful gossip is a public good seems to create a second-order collective action problem in which each has an incentive to listen but never to talk about instances of other people following or flouting socially useful norms. The problem seems insurmountable in the absence of material incentives. But it is not.

17 There are individuals in every society who get positive enjoyment from inflicting losses on others. Norms enable such individuals to satisfy this desire without enduring guilt or shame in doing so: by directing their anti-social impulses to norm-violators, would-be 'punishers' are licensed to indulge their impulses. On this account, the significance of more formal procedures of the law lies in regularizing and managing anarchic punitive activity rather than in ensuring that incentives for norm compliance are adequate.

18 Darwin vacillates between individual and group selection accounts of the evolution of guilt, shame, and embarrassment. See The Descent of Man (1871), and The Expression of Emotion in Man and Animals (1872).

19 Robert Ellickson, Order without Law (Harvard University Press, 1994). 
The second-order collective action problem is only intractable if we assume that people are purely self-interested, or that they don't get intrinsic rewards from sharing information about other people's social behaviour. But it is a familiar fact that most people enjoy gossip, are rewarded by the esteem of others for conveying socially useful gossip, and fear the disesteem that follows from being the subject of negative gossip, or from spreading false rumors.

Richard McAdams explicitly connects gossip and esteem to explain how social norms are policed in the absence of formal government. 'The conversation we call "gossip" is often experienced as a benefit, not a cost, and it usually consists of information about how others have deviated from ordinary behaviour'. ${ }^{20}$ The reasons for this psychological quirk are shrouded in our evolutionary history, though undoubtedly a plausible story can be told about how a propensity to take delight in gossip, along with our disposition to feel shame or guilt for violating social norms, would confer advantages to the members of small groups. Whatever the explanation, our desire for the esteem of others may provide the incentive to gather and reveal information about other people's rule infractions, and to publicly conform to rules ourselves. This sends signals to others that we are disposed to cooperate, and it may bring accolades from people we respect. According to McAdams, 'the desire for esteem makes it possible, though not inevitable, that the group will solve the secondorder collective action problem [of monitoring behaviour and spreading information about rule infractions]. The barrier to norm formation arises from the assumption that any sanction must be costly to impose. If one can costlessly impose a small loss on others by withholding esteem, or costlessly impose a small gain by granting esteem, there is no incentive to free ride'. ${ }^{21}$

While we agree with the gist of this view, it is clearly an overstatement to conclude that the intrinsic rewards of gossip and the pursuit of esteem remove all incentives to free ride in all cases. Unless norms are fully internalized and guilt is robust, shrewd social climbers might still break social norms in private, and people who are less concerned with the esteem of others might still free ride by failing to respond to gossip about them, or failing to spread socially beneficial gossip. This is especially true if the norm is widely viewed as outdated or unimportant, or if the person tempted to violate the norm has an attenuated sense of guilt and shame, or a low discount rate, perhaps because the costs of leaving the group or the benefits of future cooperation are low.

So far we have focused on how social norms can arise as emergent orders in the absence of formal political institutions to transform collective action problems into simple coordination games with clear equilibria. Norms make certain equilibria salient. But some equilibria are better than others.

Destructive norms, including those that began as constructive, or those that are constructive for some groups and destructive for others, can create norm traps that make nearly everyone worse off. For example, many have speculated that traditional religious rules, including those that regulate dietary and sexual habits, may have had some advantages for group members by making it clear what kinds of sexual behaviour

McAdams, above n 9, 362.

21 Ibid 364. This formulation may suggest that the suppliers of esteem and disesteem are withholding or granting esteem as a conscious activity designed to encourage the esteemed agents in norm compliance. We think that this is neither plausible nor necessary. In most cases, individual observers simply form their judgements spontaneously: observers think that the actor has behaved badly (or well). If the actor knows that the norm is in place and that the opinions of others will track his action, and he cares about the good opinion of others, he will be encouraged to comply. If you fail to wash your hands after using the public lavatory, many observers will think you are a dirty person. But their thinking this does not need to be motivated by a special concern about spreading disease. 
are kosher, and which foods are best avoided. Adding divine threats of punishment for violations helps convince group members who do not feel sufficient guilt or shame to comply for more self-interested reasons. But some of these rules, including prohibitions against homosexuality and consuming shellfish or animals with cloven hooves (both of which are forbidden in traditional Judaism), seem obsolete. Although these dietary rules may have initially helped group members avoid parasitic diseases like trichinosis (from pigs) or Salmonella (from oysters), they no longer seem to promote the welfare of anyone other than pigs and oysters. ${ }^{22}$

Other norms that are arguably destructive have more sinister origins. For example, Gerry Mackie traces the evolution of footbinding in China and female genital mutilation (FGM) in many African countries, and finds that these practices originated not to serve the interests of most members of the group but to ensure that imperial female slaves would remain faithful to their masters. Broken feet make it difficult for women to seek sexual adventures, and mutilated sex organs make it less appealing, so these are two different solutions to the same problem: keeping women close to home, and ensuring that any children they foster are from the male king, or as the practice spread, the male head of household. Mackie suggests that we need only make three plausible assumptions to support the view that footbinding and FGM could arise and persist as stable equilibria even in a society in which they harm almost everyone: that people are strategically rational, that they desire to raise their own biological children (for men there is always some uncertainty about paternity), and that there is an original condition of female slavery or extreme subservience. ${ }^{23}$

Once the convention takes hold, people will disapprove of those who do not practice it. In some countries religious leaders attach divine approval to the practice so that people who do not experience enough guilt or shame for not complying may also experience the fear of divine punishment, in addition to the prospect of being less desirable in the marriage market. Thus, even those who oppose these practices may have reasons to mutilate their daughters in order to make them attractive to suitors. Parents are caught in 'belief traps' and the entire society is caught in a 'norm trap'. Posner and Rasmusen define a 'norm trap' as a situation in which 'the transitional costs to a new norm are high enough [that] society is stuck with a suboptimal norm'. ${ }^{24}$ The cost of transition is especially high if women who resist these practices are less likely to get married, and bear and raise as many offspring as those who follow them. Even if some rebellious women can overcome the guilt, shame, and social stigma associated with violating the norm that requires her to bind her daughter's feet or cut off her clitoris, their daughters are likely to leave fewer descendants, and therefore fail to undermine the norm over the long run. This helps explain why footbinding persisted for 1,000 years in China, and FGM still flourishes in parts of Africa and the Middle East.

We will defer discussion about how to respond to destructive norms like these until the final section. The upshot of this section is that whether norms are constructive or destructive, they are usually best thought of as emergent properties, according to which the independent actions of people in a group combine to produce a macropattern that may not be the intended or preferred outcome of anyone in the group. Hayek saw such emergent patterns as a pervasive and important feature of social life:

22 Of course people who avoid these foods now do it for explicitly religious reasons, not for any health benefits. But we suggest that the origin of many such rules lies in the (perceived) benefits they once conferred to the groups of people who adopted them.

23 Gerry Mackie, 'Ending Footbinding and Infibulation: A Convention Account' (1996) 61 American Sociological Review 1010.

24 Richard A Posner and Eric B Rasmusen, 'Creating and Enforcing Norms, with Special Reference to Sanctions' (1999) 19 International Review of Law and Economics 378 


\begin{abstract}
We understand one another and get along with one another, are able to act successfully on our plans, because, most of the time, members of our civilization conform to unconscious patterns of conduct, show a regularity in their actions that is not the result of commands or coercion, often not even of any conscious adherence to known rules, but of firmly established habits and traditions. The general observance of these conventions is a necessary condition of the orderliness of the world in which we live, of our being able to find our way in it, though we do not know their significance and may not even be consciously aware of their existence. ${ }^{25}$
\end{abstract}

\title{
II EMERGENT ORDERS AND INVISIBLE HANDS
}

What is the relationship between emergent orders and invisible hands? Both are similar ways of explaining social phenomena, and on some views, they are identical. But we think they are worth distinguishing in the following way. Emergent orders are neutral with respect to human welfare, while invisible hand processes are emergent orders that serve to promote human welfare. In other words, invisible hands are one kind of emergent order.

This distinction is consistent, we think, with Adam Smith's usage. Although Smith used 'invisible hand' three times in his writings, only two of the occurrences seem to indicate an important economic insight. Smith's first use of the phrase 'invisible hand' is completely unrelated to the second two. In his History of Astronomy Smith complained that whenever Greek and Roman polytheists observed unusual events, they naively saw 'the invisible hand of Jupiter' behind them. ${ }^{26}$ In the two other occurrences of the phrase in his writings, Smith clearly has in mind a process in which the actions of independent agents, each with their own parochial goals, inadvertently produce a socially beneficial outcome. In The Theory of Moral Sentiments Smith says:

The rich only select from the heap what is most precious and agreeable. They consume little more than the poor, and in spite of their natural selfishness and rapacity, though they mean only their own conveniency, though the sole end which they propose from the labours of all the thousands whom they employ, be the gratification of their own vain and insatiable desires, they divide with the poor the produce of all their improvements. They are led by an invisible hand to make nearly the same distribution of the necessaries of life, which would have been made, had the earth been divided into equal portions among all its inhabitants, and thus without intending it, without knowing it, advance the interest of the society, and afford means to the multiplication of the species. ${ }^{27}$

In the Wealth of Nations Smith says:

By preferring the support of domestic to that of foreign industry, he [the capitalist] intends only his own security; and by directing that industry in such a manner as its produce may be of the greatest value, he intends only his own gain, and he is in this, as in many other cases, led by an invisible hand to promote an end which was no part of his intention. Nor is it always the worse for the society that it was no part of it. By

Hayek above n 7, 123. Cristina Bicchieri agrees, in a passage paraphrasing Adam Ferguson: '[m]any social norms are not the outcome of a plan or a conscious design to enact them; they emerge by human action but not by human design': Bicchieri, above n 11, 40 .

${ }_{26}$ Here is the relevant passage: 'it may be observed, that in all polytheistic religions, among savages, and in the early ages of heathen antiquity, it is the irregular events of nature only that are ascribed to the agency and power of their gods. Fire burns, and water refreshes; heavy bodies descend, and lighter substances fly upwards, by the necessity of their own natures; nor was the invisible hand of Jupiter ever apprehended to be employed in those matters'. Adam Smith, History of Astronomy (1995) §3, para 2.

271759 Book 4, chapter 1 , section 10. 
pursuing his own interest he frequently promotes that of the society more effectually than when he really intends to promote it. I have never known much good done by those who affected to trade for the public good. It is an affectation, indeed, not very common among merchants, and very few words need be employed in dissuading them from it. ${ }^{28}$

Although the invisible hand metaphor is seen by scholars as one of his greatest insights, Smith does not formally develop the idea. On our account, an invisible hand process must exhibit the following five features:

1. The process gives rise to an identifiable pattern.

2. That pattern emerges through the actions of independent agents.

3. The pattern is one that most participants do not intend to produce.

4. The pattern provides net benefits to the group that (inadvertently) produces it, or has attractive normative properties in some other sense. ${ }^{29}$

5. The pattern is surprising, unforeseen, or unpredictable by those who produce it.

We shall consider each of these in turn, and then say when norms can be construed as arising by an invisible hand process.

\section{A Patterns}

Since some of what we call patterns are merely reifications, or projections onto an indifferent universe - like the constellations in the stars or the man in the moon - we might wish to exclude merely apparent patterns as invisible hand phenomena. But perhaps we should be ecumenical about what count as patterns. All we mean by 'patterns' is the existence of a discernible regularity or structure. Notice that many structures are of no scientific significance but may appear to some people to be significant in another way. When a devout religious believer observes that a passing cloud looks like a famous prophet, an impartial observer will say that although it looks like a prophet because of the pattern of water molecules, it is not in fact a prophet. We can agree that the water molecules that comprise the cloud do exhibit a structure which resembles a prophet's face, but disagree on whether this matters. This case suggests that what constitutes a pattern is in part a scientific question, but also a question of what kinds of facts people think are important to explain and in what terms such explanations run. In the case of human welfare, the invisible hand explanation in the market case is an attempt to show how something that nearly everyone should care about comes to pass: how individuals acting for their own ends can, under the right conditions, increase the welfare of others by engaging in mutually advantageous specialization and trade. The pattern is the aggregate effect, and the explanation is a set of conjectures about the incentives created by opportunities for trade.

\section{$\mathrm{B}$ Independent agents}

Invisible hand processes always involve independent agents acting in accordance with their own preferences, beliefs, and goals. This is not to say people's goals do not impact other people, but only that each agent is acting for her own reasons, and under no duress or coercion. In Smith's first invisible hand example, the rich are said to care about nothing but getting cheap labor from the poor whom they employ, but in doing

1776 Book 4, chapter 2, section 9.

29 As in Smith's example where the good feature produced is a more equal distribution of 'necessaries'. 
so poor labourers who perceive the job as their best option, end up better off than they would have been in the absence of the selfish employer offering them the job. It is worth stressing that Smith does not think workers and employers are usually exclusively self-interested. The idea is that even under this cynical assumption, we may still get a better allocation of resources if people develop their skills and produce things that other people want in order to increase their own profits, than we would if they devoted their days to acts of charity.

\section{Without intention}

It is important, we think, to stress that some people might intend to improve social welfare when they act in the marketplace, but Smith's point is that patterns like social welfare improvements need not be intended in order for that general improvement to materialize. Thus, to count as an invisible hand process, we do not need to make the extreme claim that nobody intends a particular outcome that results from independent choices; we only need to assume that nobody needs to intend it in order to bring it about. For example, it is conceivable that some Chinese families bound their daughter's feet not simply because it made her more attractive in the marriage market in $18^{\text {th }}$ century China, but because they thought this is a pattern worth preserving. Of course, no individual has the power to preserve or destroy such a ubiquitous social norm. But it is perfectly possible to say the norm arose or persisted without most people, and in some cases all people, intending to promote the norm.

\section{Socially beneficial}

In both occurrences of 'invisible hand' in the works of Adam Smith, there is a strong implication that for a process to count as an invisible hand, it must bring benefits to the people to whom it applies. Some disagree with this usage. For example, Robert Nozick argues that 'not every pattern that arises by an invisible-hand process is desirable'. We think this matter of word usage is essentially a question of taste. The advantage of Nozick's definition is that it covers cases throughout the natural world, like Hume's account of the evolution of the universe from a few simple laws, or the popular view among biologists that mitochondria began as parasites and eventually became indispensable sources of power to virtually all organisms. But we stick with the usage traditional in economics. When all of the conditions other than (4) are present, and when the outcome is unequivocally bad rather than neutral or good, economists sometimes refer to the 'backside of the invisible hand' or what we call the 'invisible fist'. Thus, the ozone hole that developed in the 1980s from the unregulated use of chlorofluorocarbons is a paradigm case of the invisible fist: nobody who used hair spray products in California intended to raise the risk of skin cancer in Queensland by depleting part of the atmosphere, but this was the result.

\section{E Surprising}

Adam Smith suggests, and many commentators agree, ${ }^{31}$ that invisible hand explanations are in some sense surprising. Like our third criterion, this needs to be

30 Robert Nozick, 'Invisible-Hand Explanations' (1994) 84(2) The American Economic Review 315.

31 See Edna Ullmann-Margalit, 'Invisible-Hand Explanations' (1978) 39 Synthese 271; Gerald Gaus, 'Explanation, Justification, and Emergent Properties: An Essay on Nozickian Metatheory' in The Cambridge Companion to Nozick's Anarchy, State, and Utopia (Cambridge University Press, 2012); Adrian Vermeule, 'The Invisible Hand in Legal and Political Theory' (2010) 96(6) Virginia Law Review 1422. 
qualified. Invisible hands need not actually surprise everyone, especially social scientists and curious people who enjoy discovering basic principles that explain how the world works. Indeed, although invisible hand explanations are typically surprising to those who first encounter them, they become expected by experts who study them in particular domains. Once we have an explanation for how invisible hands work, we get a deeply satisfying theory, one which generates predictions that are ultimately unsurprising.

When these conditions are present, the invisible hand metaphor is apt because, as Brennan and Pettit argue, 'those who remain mere participants in the system, those who fail to adopt a theoretical stance on what happens, will necessarily fail to recognize what is going on ... Participants who are not also theorists are embedded in their individual positions, and are aware of the immediate pushes and pulls that work on them; but they lack any sense of the aggregate shape of things. ${ }^{32}$

Many have argued that evolution by natural (and sexual) selection can be thought of as an invisible hand process. Leda Cosmides and John Tooby join Robert Nozick and Friedrich Hayek in describing evolution this way, mainly because it blindly produces what appear to be designed creatures. ${ }^{33}$ The historical and conceptual link between theories of emergent order in biology and economics is profound. As Hayek reminds us, "The theory of evolution of traditions and habits which made the formations of spontaneous orders possible stands ... in a close relation to the theory of evolution of particular kinds of spontaneous orders which we call organisms, and has in fact provided the essential concepts on which the latter was built'. ${ }^{34}$

However, on our view there is an important difference between emergent orders and invisible hands, one that is occasionally obscured by the ambiguity of terms like 'fitness' and 'success' in evolutionary theory. The difference is that evolution does not necessarily produce favourable outcomes according to any widely agreed upon normative benchmark. There are two aspects to this observation. One is resistance to the idea of evolution as progress: there is simply no reason to think that dinosaurs were, in their evolutionary context, in any way 'inferior' to prevalent species in our own context. And what the participants make of the evolutionary processes to which they are subject can make no difference to how those processes work. Evolution simply operates as a blind filter. The other aspect involves recognizing that natural selection is a process that adapts organisms to particular environments, not one that makes them happy or successful in any sense other than differential numbers of surviving offspring.

Consider Darwin's discussion of natural selection (a phrase which suggests an invisible hand that selects winners and losers), in which he compares the intentional selection of animal farmers with the unintentional selection of nature:

As man can produce and certainly has produced a great result by his methodical and unconscious means of selection, what may not nature effect? Man can act only on external and visible characteristics: nature cares nothing for appearances, except insofar as they may be useful to any being. She can act on every internal organ, on every shade of constitutional difference, on the whole machinery of life. Man selects only for his own good; Nature only for that of the being which she tends ...

Geoffrey Brennan and Philip Pettit, 'Hands Invisible and Intangible' (1993) 94 Synthese 200.

Leda Cosmides and John Tooby, 'Better than Rational: Evolutionary Psychology and the Invisible Hand' (1994) 84(2) American Economic Association Papers and Proceedings 327. An accessible account of evolution by natural selection as an invisible hand process is Richard Dawkins, The Blind Watchmaker (W W Norton \& Co, 1986).

34 Friedrich Hayek, 'The Results of Human Action but not of Human Design' (1980) Studies in Philosophy, Politics, and Economics 101. 
[Man] does not allow the most vigorous males to struggle for the females. He does not rigidly destroy all inferior animals, but protects during each varying season, as far as lies in his power, all his productions. He often begins his selection by some halfmonstrous form; or at least by some modification prominent enough to catch his eye, or to be plainly useful to him. Under nature, the slightest difference or structure or constitution may well turn the nicely-balanced scale in the struggle for life, and so be preserved. How fleeting are the wishes and efforts of man! how short his time! and consequently how poor will his products be, compared with those accumulated by nature during whole geological periods. Can we wonder, then, that nature's productions should be far 'truer' in character than man's productions; that they should be infinitely better adapted to the most complex conditions of life, and should plainly bear the stamp of far higher workmanship? ? $^{35}$

Darwin anthropomorphizes Nature throughout the metaphor, and appeals to our tendency to explain the appearance of patterns by intentional action. Darwin is, ironically, using what Daniel Dennett calls the 'design stance' to destroy the argument from design. But his language may suggest to the careless reader that he thinks the organisms that emerge from the evolutionary process are better in some sense than the 'inferior' creatures farmers produce through deliberate selection. This interpretation is a mistake. By 'inferior' creatures Darwin simply means those that are less welladapted to their environment, not creatures that are less happy, or well off. ${ }^{36}$

Since fitness is just a measure of reproductive success, not social welfare, Darwin's argument suggests that the products of evolution by natural selection are emergent orders but not necessarily invisible hand processes (as we use the terms). Still, some emergent orders that arise through evolution can be described as invisible hands, since they make us better off according to widely accepted normative standards.

For example, human intelligence and compassion have arisen through a combination of natural selection, sexual selection, and gene-culture coevolution. If general intelligence is a trait that is both individually beneficial and widely valued because of its social consequences, ${ }^{37}$ and if compassion and kindness are attractive traits to both men and women, then socially beneficial consequences can result from the process of mate selection in which such consequences are neither foreseen nor intended.

By contrast, dysgenic processes in which individual choices lead to socially undesirable outcomes are the back side of the invisible hand, or the invisible fist. If, as some have argued, wealth, education, and IQ are negatively correlated with fertility (the number of children people choose to have), the growth of wealth and welfare in the modern world may inadvertently produce dysgenic effects even if each person would prefer an aggregate outcome in which future people are at least as intelligent as current people. ${ }^{38}$ As Thomas Schelling put it, 'marriage and romance are exceedingly individual and private activities, but their genetic consequences are altogether aggregate'. 39

So far we have described invisible hand processes as emergent orders that promote human welfare. This implies that norms constitute invisible hands when they are welfare-promoting emergent orders. How might they do this? One example is Robert Ellickson's argument that, over time, norms in close-knit communities tend to

35 The Origin of Species (Barnes and Noble Classics, 2003) 76-77.

36 And since the environment of farm animals involves farmers who are cultivating the species for its capacity to produce food other people want to consume, it seems clear that farm animals are evolving to fit their actual environment better than the variants which are bred out.

37 Nicholas Mackintosh, IQ and Human Intelligence (Oxford University Press, 2011).

38 For an overview of the evidence and some possible responses to the problem, see Jonny Anomaly, 'Public Goods and Procreation' Monash Bioethics Review (forthcoming).

39 Schelling, above n 15, 140. 
evolve in ways that maximize the efficient use of scarce resources. ${ }^{40}$ In a famous case study, Ellickson examined how cattle ranchers in Shasta, California settle disputes involving cattle straying from one farm to another and inflicting damage on neighboring property. What he found is that farmers tend to rely on informal rules that are enforced through social rather than legal sanctions. Even when laws were passed, he observed that ranchers either deliberately ignored them or were ignorant of their existence. Among the reasons he gives for this are: the cost of taking legal action (transaction costs and monetary costs); that laws may be less efficient solutions than norms that emerged from a trial-and-error process; and the fact that norms created within a community tend to have more perceived authority over those who live there than externally imposed laws.

One reason people are frequently willing to ignore law is that they often possess more expeditious means for achieving order. For example, neighbors in rural Shasta County are sufficiently close-knit to generate and enforce informal social norms to govern minor irritations such as cattle-trespass and boundary-fence disputes. This closeknittedness enables victims of social transgressions to discipline deviants by means of simple self-help measures such as negative gossip and mild physical reprisals. Under these circumstances, informal social controls are likely to supplant law. ${ }^{41}$

Ellickson takes the argument further and suggests that laws passed by legislatures can undermine socially beneficial norms, and that 'lawmakers who are unappreciative of the social conditions that foster informal cooperation are likely to create a world in which there is both more law and less order'. ${ }^{42}$

We do not wish to defend the more optimistic part of Ellickson's thesis - the idea that social norms tend to be efficient in close-knit groups. In fact, we find Ellickson's general claim implausible if it is taken to imply that we should generally defer to norms rather than laws. People can become ensnared in local rather than global optima; some groups can maintain destructive norms for long periods of time; most norms emerge locally with their path-dependent properties tracking local conditions and seem unlikely to be sufficiently sticky to bind together the millions of independent actors in modern nation states. Instead, we take Ellickson's case study to illustrate the importance of understanding norms as emergent orders, and of separating socially beneficial emergent orders (invisible hands) from socially destructive emergent orders (invisible fists).

It is, we think, useful to distinguish between processes that emerge invisibly and processes where outcomes are sustained invisibly. ${ }^{43}$ When Adam Smith describes the market order and the highly beneficial division of labor to which it gives rise, he talks both of how that order arose in the first place - as the "very slow and gradual consequence' of a possibly 'original principle in human nature' - and of how the equilibria in that emergent order are preserved. Participants in markets typically have no regard to the normative properties of the equilibrium prices and quantities that emerge from competitive market processes; each simply does the best she can for herself.

To see the distinction at stake here, consider another familiar process - that of electoral competition under broadly democratic processes. The requirement to be

By 'efficient' Ellickson has in mind Kaldor-Hicks efficiency, according to which norms tend to maximize net social welfare even if they result in losses for some members of the group, especially in the short run. Ellickson's thesis resembles Posner's conjecture that the common law tends toward efficiency.

41 Ellickson, above n 19, 282.

42 Ibid 286

43 This distinction is made by Ullman-Margalit, above $\mathrm{n} 31$. 
elected provides incentives for candidates or contending parties to formulate policies that are believed to be attractive to voters (or strategic groups of them) even if the candidates themselves are motivated predominantly by a desire to further their own political careers. There can be a substantial mismatch between the motives of political agents and the normative justification for the ultimate outcomes. We might then refer to democracy as constituting an invisible hand process, at least in part. But that description - and the question of how well the incentive structure imposed by electoral competition works to produce outcomes that track voter interests - is perfectly consistent with democratic institutions being designed and chosen 'visibly'. Shrewd and well-motivated 'founding fathers' may have designed the institutions under which in-period politics operates specifically with an eye to those institutions' normative properties: but at the in-period level, ambitious political candidates and ordinary voters may be operating with much more self-interested considerations predominant. In that sense, constitutional democracy did not emerge invisibly; but it may operate invisibly.

\section{NORMS AND LAWS, LIBERTY AND WELFARE}

The main difference between laws and norms, as we understand them, is that laws can be enforced by a central government that has a monopoly on the legitimate use of force, whereas norms are created and enforced with informal social sanctions. This makes it more plausible to describe norms as emergent orders since they typically arise in situations in which no one in a group has the power to unilaterally impose rules on everyone else in the group.

But laws can also be thought of as emergent orders of a certain kind, especially in representative governments. Public choice theorists often describe laws as the byproducts of actions lawmakers perform in order to win elections. Laws are, to a large extent, constrained by the wishes of citizens, the incentives created by political institutions, and the prospect for politicians of electoral success or failure. Some laws are simply a codification of widely accepted norms - for example, against murder, theft, and unprovoked violence; and other laws emerge from the decisions of judges. Judges often defer to precedent, and to widely shared norms. This suggests that any particular law in a representative government is shaped by the actions of many different people, with their own individual preferences. But because the state has the power to create and enforce its laws as a singular entity, we think it is worth retaining the (typically exaggerated) conceptual distinction between norms as emergent orders and laws as externally imposed directives. ${ }^{44}$

Norm optimists (like Elinor Ostrom and Robert Ellickson) tend to think we should give more scope to markets rather than politics, so that groups of people can be left free to develop efficient solutions to local problems. Norm pessimists (like Eric Posner and Richard McAdams) tend to emphasize nasty norms that become entrenched in cultures that would be better off without them: they think laws are often a more effective way to enhance social welfare, individual liberty, and other widely shared values. Like the distinction between bottom-up norms and top-down laws, the distinction between optimists and pessimists is a bit overblown. After all, norm optimists recognize that the populations of modern states are often too big and diverse

44 Moreover, laws themselves operate within a highly structured network of norms - ones that run from the professional norms of judges and lawyers and police to the norms of the general community that allow government to have its 'monopoly on the legitimate use of force' in the first place. When the term 'legitimate' is used here, it refers not so much to what the law says about what officers can do, but to what those subject to the laws will let them do. In well-ordered political societies many people seem to obey the law because it is the law: they assign to the law a certain normative authority. They treat the police as entitled to be obeyed and treat court procedures as entitled to settle disputes. 
for norms to solve large scale collective action problems, and norm pessimists recognize that political solutions have their own problems. According to Ellickson, 'the key difference between [norm optimists and pessimists] appears to be that the optimists have less confidence than the pessimists that government can outperform social forces in reforming inefficient norms'. ${ }^{4}$

We are neither optimistic nor pessimistic about norms. Instead, we argue that scholars and legislators in representative governments should consider the following questions when thinking about whether to rely more heavily on laws or norms, or harness the power of law to indirectly encourage or discourage the evolution of norms.

\section{A How urgent and widespread is the problem?}

Scholars from Elinor Ostrom to Robert Ellickson have argued that members of a community engaged in repeat interactions will usually find an informal arrangement for solving problems that arise with alternative uses of natural resources. Among the usual provisos are that the relevant actors must have a sufficiently low discount rate to justify cooperation, and that social sanctions attached to norm violations must be strong enough to induce compliance.

However, many of the evolutionary views shared by norm optimists rely on a lengthy trial-and-error process during which different norms are tried out until the group converges on a mutually beneficial equilibrium. But when a challenge that requires collective action stems from an imminent threat to a large and diverse group, social norms may not emerge in time to solve the problem. This can be true for the spread of an infectious disease like SARS in China in the 1990s, or the sudden collapse of a population of animals like the American Bald Eagle in the mid- $20^{\text {th }}$ century. While social norms can help preserve an endangered species or reduce the threat of an infectious disease, they are typically not as effective as state-sponsored efforts in representative governments whose leaders have the power to coerce, and to impose uniform rules with credible sanctions. This is not to say that states should spend any amount of money to save an endangered species or control an infectious disease, only that social evolution may be too slow a process to rely on for urgent collective action problems.

\section{B Are there inter-group or inter-generational externalities?}

Externalities are a pervasive part of social life. But not all externalities matter from a moral standpoint, and some negative externalities are more efficiently addressed through social norms rather than legal requirements. As a rule of thumb, Adrian Vermeule suggests that 'norms are most plausibly efficient within close-knit groups of repeat interactors who collectively bear both the costs and benefits of the norms they create, so that the group's internal norms do not impose significant externalities. Yet such groups are the exception rather than the rule in large scale modern economies. ${ }^{46}$ For this reason, two kinds of inter-group externalities might merit legal intervention rather than reliance on norms to achieve welfare improvements.

Ellickson, above n 10, 36. Like Ostrom and Ellickson, Hayek's view is not grounded in reverence for authority or tradition, but stems from the belief that, at least much of the time, social norms survive because they solve problems that we fail to understand, and which we lack the ability to solve by relying on experts who may be over-confident in their own wisdom: 'Far from assuming that those who created the institutions were wiser than we are, the evolutionary view is based on the insight that the result of experimentation of many generations may embody more experience than any one man may possess': Hayek, above n 7, 122.

46 Vermeule, above n 31, 1438. 
First, when a set of norms benefits one group at the expense of another, the norms may be worth altering or supplanting with legal requirements or prohibitions. For example, if one group of people that lives upstream from another catches all of the desirable fish from the river and then floods the river with human waste, the result may be unfair for the group that lives downstream, and socially inefficient when considering the aggregate welfare of both groups. Yet the norms may constitute a social optimum for the upstream group.

Second, when a group's norms impose significant negative externalities on future people, there may be reason to use legal mandates to reduce these harms. Obvious cases include current people using scarce resources in a way that maximally benefits themselves at the expense of future people. Anthropogenic climate change, the evolution of antibiotic resistant bacteria, and species extinction are all cases in which current action can threaten future people in ways that may be nearly impossible for social norms alone to solve. We do not mean to suggest that all negative externalities should be eliminated, since they may be part of a process which has compensating benefits. Instead, we suggest that when current practices impose net negative externalities on future people norms are often insufficient to solve the problem.

This is partly a function of numbers. When a public good like the preservation of an endangered species or an effective antibiotic requires the coordination of a large and diverse number of people, most people will lack the incentive to make the relevant sacrifices, even if a norm requires them to do so. One reason is the free rider problem, which occurs when each person has an incentive to indulge in a socially costly activity that he would prefer everyone not to engage in. Another is the assurance problem, which occurs when people are willing to sacrifice to produce an outcome that is good for current or future people, but lack the assurance that enough others will sacrifice to make their effort worthwhile. For example, in some circles social norms require us to spend more money to buy a fuel efficient car or an energy efficient light bulb. Many of us happily comply with such norms, but most people either lack the money or the desire to do so under conditions in which the benefits of conservation are socialized but the costs are internalized. By prohibiting or taxing socially costly activities, laws can, in principle, help us converge on a salient equilibrium that is both fair and efficient - across groups, and generations.

This is not to say that efficiency is all that matters. Far from it, values like liberty and autonomy should also be considered when thinking about when to rely on emergent norms or formal laws. And the claim that government action can give rise to fair and efficient equilibria does not show that government action will have that effect.

\section{Do existing norms threaten liberties that are important for human autonomy?}

When there is a trade-off between individual liberty and social welfare, or when liberty is not sufficiently respected by communal norms, the state might intervene with privacy laws, or more generally, constitutional guarantees like the American Bill of Rights. We should distinguish two cases of norms that might interfere with important kinds of liberties: nosy norms, and norms that encourage us to pursue positional goods.

\section{Nosy Norms}

As social creatures, we often have strong opinions about how other people live their lives. This can be beneficial, as when parents and teachers encourage children to develop habits that are likely to benefit them later on but which they fail to understand now. But this disposition has a dark side. For example, growing up in a religious community may provide social benefits, psychological security, and even material 
welfare, especially for the poor and disabled. But it can also be oppressive for deviants who are treated with suspicion and hostility.

Coming out as an atheist or homosexual can be personally liberating, but nearly impossible if the predictable social sanctions are severe. Among the sanctions may be foregone job opportunities, public humiliation by former friends and family, and even ostracism and informal punishment by religious authorities (for example, long before Saudi Arabia made it a capital crime to consume alcohol or convert to Christianity, clerics harshly enforced religious traditions, or norms, that prohibited such activities). Even if abstaining from alcohol or conforming to a set of religious requirements makes a community function more efficiently, at least in the short run, these norms are obviously oppressive to some community members.

Autonomy can be enhanced in cases like this through constitutional protections of religious and sexual minorities, or statutes that grant religious freedom and remove the state's ability to choose which set of religious traditions it wishes to support. Less direct ways of undermining norms that are corrosive to autonomy is to create privacy laws that make it illegal for citizens, employers, clerics, and other authority figures to access or spread certain kinds of information about people. Even in the absence of religious toleration, privacy laws can make it harder for the conformists to deprive dissenters of important social and economic opportunities. ${ }^{47}$

\section{Positional Goods}

Some norms solidify rather than solve collective action problems. In particular, some norms lead us to act in ways that are individually beneficial, given the actions of other people, but socially harmful. Positional goods are a clear case in which other people's actions, and expectations, can make all of us worse off. For example, since people around the world find youthful appearance attractive, ${ }^{48}$ many spend time and money wearing makeup and high heels, using expensive hair dyes and skin creams, whitening teeth, and removing wrinkles with risky and costly cosmetic surgeries.

To be sure, social norms sometimes solve collective action problems associated with positional goods. For example, counter-culture hippies in 1960s San Francisco wore unkempt beards and long hair, and rejected makeup and designer clothes in order to distinguish themselves from what they saw as the materialism of mid-twentieth century Americans. But cases like this are rare and transitory, so perhaps socially destructive norms should be taxed or banned. Some scholars emphasize the ubiquity of positional goods, and support using laws that raise the cost of positional goods. ${ }^{49} \mathrm{We}$ do not disagree with this, in principle, but it is worth emphasizing that government intervention can make the problem worse. First, laws require resources to enforce, and enforcing laws against high heels and makeup, for example, might be both expensive and ineffective if people turn to black markets and homemade beauty products to satisfy their preferences. Unless the law carries serious penalties, it is likely to be ignored, and if it did carry serious penalties, it would create new harms by encouraging

47 See McAdams, above n 9, 424.

48 The evolutionary reason men are attracted to youthful appearance is that younger women are typically more fertile. The evolutionary reason women care less about youthful appearance is that men's fertility does not decline quite as steeply with age, and because women - who spend more resources bearing and raising children - must be far more careful about who fathers their children. This makes them more likely to seek out signs of success more than fertility. Thus, men are usually under less pressure to chase the positional good of youthful appearance, though they may be under more pressure to chase the quasi-positional good of financial success. See Geoffrey Miller, The Mating Mind (Anchor, 1999).

49 See especially Robert Frank, Choosing the Right Pond: Human Behaviour and the Quest for Status (Oxford University Press, 1987). 
the usual maladies associated with black markets (assuming some inelasticity in the demand for cosmetics). Second, empowering law makers to decide which positional goods to ban or tax provides them with powers that we may prefer them not to have. Some argue that the pursuit of higher education is a positional good (and in some cases, they are right), but most of us do not think education should be taxed to avert educational arms races, in part because policymakers typically lack the information and incentives to distinguish socially valuable from socially harmful degree programs.

\section{Is the norm a local optimum when a global optimum is achievable at low cost?}

In strategic interactions with many participants and many equilibria, it is easy to understand how people can be caught in norm traps, or local optima, when other welfare-enhancing norms are available. We have already described norms surrounding pollution disposal, footbinding, and female genital mutilation, as impure coordination games with multiple equilibria. Another interesting norm is the social expectation (which became a legal requirement in some societies) that each man must pay a 'brideprice' to the family of the woman whom he wishes to marry. This practice is so common that it was standard in most preindustrial societies, and persists in many parts of Africa today. The complementary practice that requires the family of women to pay a 'dowry' to the man's family as a condition of marriage became increasingly prevalent in India during the $20^{\text {th }}$ century. ${ }^{50}$

Some have argued that the practice of brideprice is associated with a strong female role in agriculture, and that dowry is associated with societies in which women have a smaller role in labour-intensive agriculture. ${ }^{51}$ There also appears to be a correlation between brideprice and polygyny, and between dowry and monogamy. In societies that practice it, a brideprice is typically seen as the cost a husband pays to his wife's family in exchange for her household labour, whereas dowry is often paid by a woman's family to a man's family in exchange for her opportunity to marry into a family of 'superior' social rank. More recently, in some societies, groomprices (direct cash payments to the groom rather than his family) have become prevalent ways for women to increase their social standing. The evolution of norms surrounding marriages may very well be efficient responses to local conditions, but in many cases they are local optima in an unfair game. This is true when they evolve against a backdrop in which women lack access to education or property.

When we look at the game more globally, so to speak, we might argue that all of the local equilibria are inferior to an alternative equilibrium in another game. That other game is one in which women are given equal opportunities to own and inherit property, to seek education, and participate in the workforce. Under these conditions conditions of more equal rights and bargaining power - women would not be forced by circumstance to seek men in higher social classes, or come up with enough money to pay a groom for increased life prospects. But these conditions, and the game itself, may benefit from legislation that ensures property rights and bodily autonomy for each individual, rather than letting norms evolve organically, or simply passing ad hoc laws that attempt to reduce the murder of brides whose family pays insufficient dowry, which appears to be the current response in India and Bangladesh.

50 Siwan Anderson, 'The Economics of Dowry and Brideprice' (2007) 21(4) The Journal of Economic Perspectives 151.

51 Ibid 156. 
E How quickly are destructive norms likely to change in the absence of state intervention?

Impersonal laws are often better than norms when groups are large or diverse. But laws can also supplement norm change, and for many of the most troubling norms, the most effective state response may be to indirectly facilitate norm change.

Consider again the case of footbinding in China and FGM in Africa. Gerry Mackie argues that although laws against footbinding probably had some effect in hastening the process of subverting the norm, the work of anti-footbinding societies was much more important. According to Mackie, these societies did three things:

First, they carried out a modern education campaign, which explained that the rest of the world did not bind women's feet - that China was losing face in the world and was subject to international ridicule. Second, their education campaign explained the advantages of natural feet and the disadvantages of bound feet. Third, they formed natural-foot societies, whose members pledged not to bind their daughters' feet nor to let their sons marry women with bound feet. $^{52}$

If this is right, the best state action may be to simply allow norm entrepreneurs and public health practitioners to go to work. Outlawing the practice may send a signal of social disapproval to those who think the government is a source of moral authority, but it fails to address the underlying strategic problem unless it enforces legal prohibitions vigorously.

The demise of footbinding as a social norm seems to have occurred in part because of information cascades, which altered the strategic considerations parents faced in deciding how to make their daughters attractive in the marriage market. According to Cristina Bicchieri, 'informational cascades occur when it is optimal for an individual, having observed the actions of other individuals, to follow their behavior regardless of his own preferences or information'. ${ }^{53}$ Once parents understood the alternatives, all they needed was some assurance that enough other people around them would decline to bind their daughters' feet. Anti-footbinding societies could make agreements credible in close-knit communities, even in the absence of state enforcement. As soon as enough parents complied with the new norm, the older and less socially efficient norm vanished. On Mackie's view, similar societies are likely to be effective at ending FGM in African countries where legislation has had little effect. States can facilitate this process by allowing public health professionals to spread information, in addition to outlawing the practice, which has so far been unsuccessful. $^{54}$

\section{F What are the limits of the law?}

The evaluation of norms as instruments of social order should be posed as a comparative exercise. It is a familiar conceptual point - much emphasized by public choice theorists - that the mere observation that a norm is not working 'optimally' is not sufficient to justify legal intervention. The aphorism that, to a man with a hammer everything looks like a nail, is applicable here. Policymakers and lawmakers are perhaps inevitably psychologically disposed to think that policy and law are appropriate solutions to all observed problems. In other words, people in the business

52 Mackie, above n 23, 1011

53 Bicchieri, above n 11, 197.

54 Mackie, above n 23, 1014. 
of law and policy tend to be blind to the limitation of their own tools. ${ }^{55}$ Just what these limits are is a matter of normative significance and considerable intellectual interest, but we cannot say much about the question here. But it is worth emphasizing the various gaps between what might be construed as the ideal policy or the ideal law and what gets realized on the ground. In particular:

(a) The ideal law many not be the law that is most likely to emerge from political processes. Those processes involve inevitable compromises between the interests of specific influential bodies, and with what an often ill-informed electorate can be induced to vote for, and what vote-hungry politicians can be induced to promote. What finally emerges as law may lie a long way from what the original designer has in mind.

(b) The actual law that emerges from the political process has to be interpreted by judges, who may have their own biases and agendas.

(c) The law as it applies 'on the street' will be subject to the culture of the police force. There must remain an element of discretion that lies with individual police officers and their decisions as to which laws to enforce and whom to focus their enforcement efforts on.

(d) The behavioural response by the general public can be unpredictable compliance can be secured in ways that legislators did not intend, or actions to avoid or evade the law can have worse effects than the actions the law is designed to proscribe.

None of these considerations means that legislative (or other policy) intervention in the face of defective norms is unduly dangerous or presumptively inappropriate. It is merely to underline a set of considerations that policymakers and legislators, by virtue of their location in the law-making process, are disposed to overlook or underestimate.

\section{CONCLUSION}

Our object in this paper has been to explore the role of social norms as possible sources of social order - mainly with an eye to the contrast between norms and legislation. We have argued that many social norms function as invisible hands, or socially beneficial emergent orders. But equally, we have conceded that norms can be perverse. They can continue to operate when the conditions that favoured their emergence have long since changed. They can support conditions that significantly favour some groups over others. They can even serve to make almost everyone who is subject to them worse off. And we have emphasized that, though it may be tempting to think of legislation and the processes by which legislation is generated and implemented as lying beyond and above the operation of social norms, this view is mistaken. There is no deus ex machina available.

We are suspicious of drawing any general conclusions from accounts of instances where norms have worked well - where they seem to have solved coordination or prisoner's dilemma problems (or what might have been such problems if the relevant norms had not been in play). We do think that there is an important distinction between large number and small number interactions and that norms are more likely to arise and prove stable in small number cases. Where norms emerge locally, there is likely to be

55 Even when they are not blind, they may be induced to background such limits in their public conduct. How many politicians have, for example, been forced to intervene in situations that they believe they should not because to 'fail to act' would be seen by the general public as an inadmissible confession of the politicians' own impotence! 
an important adjudicative role for government action (and possibly legislation) as the distinct norms of local groups come into conflict.

On the other hand, any broad evaluation of norms as sources of social order should ask the 'compared to what?' question. The limits and imperfections of norms must be set against the necessary limits and imperfections of legislative 'solutions'. Those limits and imperfections are not always obvious to those who design such solutions. By their nature, 'visible' processes tend to have more advocates than 'invisible' processes - that is just part of the upshot of being 'invisible'. In that sense, norms may have more going for them than many legislators and would-be policy advisors are apt to recognize. 